\section{OP0036 STRUCTURAL LESION ON MRI OF THE SACROILIAC JOINTS IN AXSPA PATIENTS WITH IBP}

Manouk de Hooge $^{1,2}$, Ann-Sophie De Craemer ${ }^{1,2}$, Thomas Renson ${ }^{1,2}$ Philippe Carron $^{1,2}$, Liselotte Deroo ${ }^{1,2}$, Dirk Elewaut ${ }^{1,2}$, Filip van den Bosch ${ }^{1,2}$. ${ }^{1}$ Ghent University Hospital, Ghent, Belgium; ${ }^{2}$ VIB Inflammation Research Center, Ghent, Belgium

Background: HLA-B27 and sacroiliitis on MRI form the basis of the Assessment of SpondyloArthritis international Society (ASAS) axial spondyloarthritis (axSpA) classification criteria. In addition, while not an entry criterion of the classification criteria, inflammatory back pain (IBP) is fundamental in the axSpA diagnostic process and it is endorsed as referral parameter in primary care. Besides inflammation on MRI, which is the hallmark of axSpA, there is still debate on the value of structural MRI lesions in these patients.

Objectives: To report on MRI of the sacroiliac joints (MRI-SIJ) findings in newly diagnosed axSpA patients stratified for the presence of IBP and HLA-B27 positivity. Methods: Newly diagnosed and anti-TNF naive axSpA patients of an ongoing Belgian (Be-Giant) cohort were included in this study. MRI-SIJ assessment was performed independently by 3 calibrated readers according to an adapted method of the Spondyloarthritis Research Consortium of Canada score, evaluating erosions, fatty lesions, sclerosis and ankylosis (T1-weighted and STIR images viewed simultaneously). Also, the ASAS definition of a positive MRI-SIJ was evaluated. MRI sum scores were calculated as 2 out of 3 (median) reader scores.

Results: In 138 axSpA patients MRI-SIJ data was available; 68 (49.3\%) patients were male, 104 (75.4\%) HLA-B27 positive and 131 (94.9\%) patients fulfilled the IBP criteria according to ASAS. In the IBP+ patient groups, a large amount of structural MRI lesions were seen. In these groups, erosions are most frequently reported, with an average extent of 5 erosions. IBP- patients were rarely seen in this cohort and erosions and fatty lesions were the only structural lesions observed in these patients, with a much lower extent compared to the IBP+ patients (see table 1). There were no axSpA patients with negative MRI-SIJ, negative HLA-B27 and without IBP.

Conclusion: In this cohort of newly diagnosed anti-TNF naïve axSpA patients, structural lesions are frequently and with a high extent seen in IBP+ patients. Only in the IBP + axSpA patients the previously reported threshold for axSpA patients of $\geq 3$ erosions and $\geq 3$ fatty lesions is maintained, as IBP- axSpA patients have far fewer lesions. IBP seems to be an indicator for the presence of structural MRI-SI lesions in newly diagnosed axSpA patients.

Table 1. Structural lesions seen on MRI in axSpA patients stratified for IBP, HLA-B27 and a positive MRI-SIJ

\begin{tabular}{|c|c|c|c|c|c|c|c|c|}
\hline $\begin{array}{l}\text { Structural MRI } \\
\text { lesions }\end{array}$ & $\begin{array}{l}\text { IBP+ } \\
\text { MLAB27+ } \\
\text { MALI-S1+ } \\
\text { n=77 }\end{array}$ & $\begin{array}{l}\text { IBP+ } \\
\text { HLAB27+ } \\
\text { MA1-SI- } \\
n=22\end{array}$ & \begin{tabular}{|l} 
IBP+ \\
HLAB27- \\
MRIISI+ \\
$\mathrm{n}=27$
\end{tabular} & $\begin{array}{l}\text { IBP+ } \\
\text { HLAB27- } \\
\text { MRR-SI- } \\
\text { n=5 }\end{array}$ & $\begin{array}{l}\text { IBP- } \\
\text { HLAB27+ } \\
\text { MRl-SI+ } \\
\text { n=3 }\end{array}$ & $\begin{array}{l}\text { IBP- } \\
\text { HLAB27+ } \\
\text { MREl-SI- } \\
\text { n=2 }\end{array}$ & $\begin{array}{l}\text { IBP- } \\
\text { HLAB27- } \\
\text { MRR-SI+ } \\
n=2\end{array}$ & $\begin{array}{l}\text { IBP- } \\
\text { HLAB27 } \\
\text { MRI-SI- }\end{array}$ \\
\hline Gender, $n(\%)$ male & 41 & 13( & 9( & $2(40.0 \%)$ & $1(33.3 \%)$ & $\%$ & $1(50.0 \%)$ & \\
\hline Erosions ${ }^{*}$ & $\begin{array}{l}61(79.2 \%) ; \\
5.3 \pm 4.9\end{array}$ & $\begin{array}{l}8(36.4 \%) \\
4.9+6.6\end{array}$ & $\begin{array}{l}20(74.1 \%) ; \\
5.2+4.4\end{array}$ & $\begin{array}{l}2(40.0 \%) \\
50057\end{array}$ & 1(33.3\%); & $1(50 \%) ;$ & $1(50 \%)$ & 0 \\
\hline Fatty lesions" & $\begin{array}{l}23(29.9 \%) ; \\
8.6 \pm 7.0\end{array}$ & $\begin{array}{l}5.22 .7 \%) ; \\
12.0 \pm 7.7\end{array}$ & $\begin{array}{l}4(14.8 \%) ; \\
13.0 \pm 5.3\end{array}$ & $\begin{array}{l}3.000 \% \\
2.3 .00 \%)\end{array}$ & $\begin{array}{l}1.050 \%) ; \\
2.00 \mathrm{NA}\end{array}$ & $\begin{array}{l}1.00 \%) ; \\
2.0 \pm N A\end{array}$ & $\begin{array}{l}1(150 \%) \\
3.0 \pm N A\end{array}$ & 0 \\
\hline Sclerosis* & & 0 & & $2(40.0 \%)$ & 0 & 0 & 0 & 0 \\
\hline Ankylosis" & $\frac{4.43 .1 ;}{10(13.0 \%) ;}$ & $\begin{array}{l}2(9.1 \%) ; \\
32.0+11 ;\end{array}$ & \begin{tabular}{|l}
$3.0 \pm 1.6$ \\
$2(7.4 \%)$ \\
80.57
\end{tabular} & $11.5 \pm 5.0$ & 0 & 0 & 0 & 0 \\
\hline
\end{tabular}

numbers reported are: number of patients with 1 or more of the given structural lesion (\% from group total); mean \pm standard deviation of patients with 1 or more of the given structural lesion.

Disclosure of Interests: Manouk de Hooge: None declared, Ann-Sophie De Craemer: None declared, Thomas Renson: None declared, Philippe Carron: None declared, Liselotte Deroo: None declared, Dirk Elewaut: None declared, Filip van den Bosch Consultant for: AbbVie, BMS, Galapagos, Janssen, Lilly, Merck, Novartis, Pfizer and UCB, Speakers bureau: AbbVie, BMS, Janssen, Lilly, Merck, Novartis, Pfizer and UCB.

DOI: 10.1136/annrheumdis-2019-eular.2424

\section{OP0037 ASSOCIATION BETWEEN BONE MARROW EDEMA AND STRUCTURAL PROGRESSION IN THE SAME QUADRANT IN AXIAL SPONDYLOARTHRITIS - 5- YEAR DATA FROM THE DESIR COHORT}

Santiago Rodrigues-Manica ${ }^{1,2}$, Alexandre Sepriano ${ }^{2,3}$, Sofia Ramiro ${ }^{3,4}$, Robert B M. Landewé ${ }^{5}$, Pascal Claudepierre ${ }^{6}$, Anna Moltó ${ }^{7}$, Maxime Dougados ${ }^{7}$, Miranda van Lunteren ${ }^{3}$, Désirée van der Heijde ${ }^{3}$. ${ }^{1}$ Hospital Egas Moniz, Lisbon, Portugal; ${ }^{2}$ CEDOC, Lisboa, Portugal; ${ }^{3}$ Leiden University Medical Center (LUMC), Leiden, Netherlands; ${ }^{4}$ Zuyderland Medisch Centrum, Heerlen, Netherlands; ${ }^{5}$ Academic Medical Centre, Amsterdam, Netherlands; ${ }^{6}$ Hôpital Henri-Mondor Ap-Hp, Créteil, France; ${ }^{7}$ University Paris Descartes, Paris, France

Background: The overall presence of inflammation in the MRI-SIJ is associated with overall 5-year radiographic damage in patients with axSpA ${ }^{1}$. But we do not know if a bone marrow edema (BME) lesion leads to a structural lesion at the same place (i.e. in the same quadrant).

Objectives: To investigate the association between BME and structural progres sion in the same quadrant of the SIJ, over time.

Methods: Patients from the DESIR cohort (early axSpA according to the rheu matologist) with $\geq 2$ consecutive MRI-SIJ (out of baseline, 2 and 5 years), were included. Each image was independently scored by 3 trained central readers blinded to chronological order. BME was considered present in a time point if detected in $\geq 1 / 6$ slices in each of the 8 quadrants. The prevalence of BME (yes/ no) and structural lesions (sclerosis, erosions, fatty lesions and ankylosis; all yes/no) defined, per quadrant, by the agreement of $\geq 2$ out of 3 readers, was described at BL and at 5 years. The longitudinal association between BME and each of the structural lesions in the same quadrant was tested in time-lagged multilevel Generalized Estimating Equation (GEE) models with autoregression taking individual reader data into account, and adjusting for clinical variables selected a priori on clinical grounds (age, gender, disease activity and treatment).

Results: In total, 197 patients were included (age 34 (SD 9) years, 48\% male and $61 \%$ HLA-B27 positive). While BME and fatty lesions were evenly distributed across quadrants, erosions and sclerosis occurred preferably in the iliac side (i.e. Q1 and Q4) (Table 1). The prevalence of BME decreased over time (baseline range: $11 \%-16 \%$; 5 -year range: $7 \%-14 \%$ ), while erosions (baseline range: $2 \%$ $23 \%$; 5 -year range: $3 \%-28 \%$ ) and especially fatty lesions (baseline range: $4 \%$ 14\%; 5-year range: $9 \%-21 \%$ ) increased. Ankylosis and sclerosis were rare in this early axSpA cohort. In the multivariable models, BME was longitudinally associated with sclerosis (OR:1.7 $(95 \% \mathrm{Cl}: 1.0 ; 3.2))$, erosions $(2.0(1.5 ; 2.5))$ and fatty lesions $(1.7(1.1 ; 2.5))$. The possible association with ankylosis could not be tested due to too low number of lesions (Table 2).

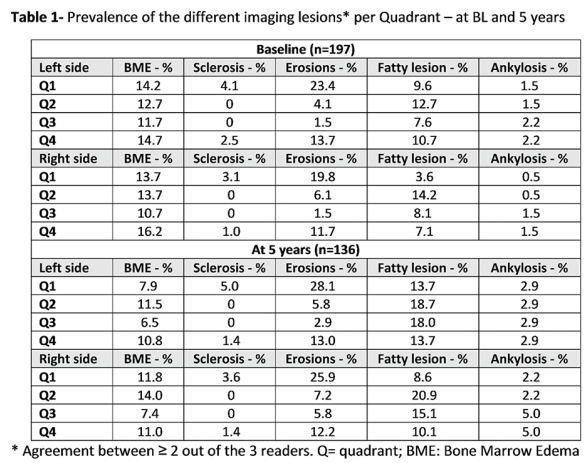

Table 2 - Longitudinal association between BME and structural outcomes in the same quadrant

\begin{tabular}{|l|c|}
\hline \multicolumn{1}{|c|}{ Outcome } & Binomial GEE - OR [95\% CI] \\
\hline Sclerosis & $1.7(1.0 ; 3.2)$ \\
\hline Erosion & $\mathbf{2 . 0}(1.5 ; 2.5)$ \\
\hline Fatty & $1.7(1.2 ; 2.5)$ \\
\hline Ankylosis & (not convergent) \\
\hline a: Multievel (reader, time, side, quadrant) with auto-regression and ajjusted for he following variables: \\
age, sex, ASDAS and treatment (NSAIDs, steroids, cSDMARDs, and TNFi). ASDAS and treatment are
\end{tabular}

Conclusion: We here demonstrate that in early axSpA-patients inflammation in one SIJ quadrant leads to structural damage in the same quadrant. This finding reinforces the pathophysiological implications of inflammation in axSpA

\section{REFERENCE:}

[1] Dougados, et al. Ann Rheum Dis. 2017;76(11):1823-1828.

Disclosure of Interests: Santiago Rodrigues-Manica Grant/research support from: Novartis, MSD, Speakers bureau: Novartis, Alexandre Sepriano: None declared, Sofia Ramiro Grant/research support from: MSD, Consultant for: AbbVie, Lilly, MSD, Novartis, Pfizer, Sanofi, Speakers bureau: AbbVie, Lilly, MSD, Novartis, Pfizer, Sanofi, Robert B.M. Landewé: None declared, Pascal Claudepierre Consultant for: Honoraria from Novartis as steering committe of this survey, Anna Moltó: None declared, maxime dougados Grant/research support from: El Lilly and Company, Pfizer, AbbVie, and UCB Pharma, Consultant for: Eli Lilly and Company, Pfizer, AbbVie, and UCB Pharma, Miranda van Lunteren: None declared, Désirée van der Heijde Consultant for: AbbVie, Amgen, Astellas, AstraZeneca, Bristol-Myers Squibb, Boehringer Ingelheim, Celgene, Daiichi, Eli-Lilly, Galapagos, Gilead, GlaxoSmithKline, Janssen, Merck, Novartis, Pfizer, Regeneron, Roche, Sanofi, Takeda, Union Chimique Belge DOI: 10.1136/annrheumdis-2019-eular.5023 